\title{
Postoperative immune response and surgical stress in selective neck dissection: Comparison between endoscopically assisted dissection and open techniques in cT1-2N0 oral squamous cell carcinoma
}

\author{
Song Fan ${ }^{\text {a, b, } 1}$, Jiang-long Zhong ${ }^{\text {a, }}{ }^{\text {, Wei-xiong Chen }}{ }^{\text {a, }}{ }^{\text {, Wei-liang Chen }}{ }^{\text {a, }}{ }^{* *}$, \\ Qun-xing Li ${ }^{\text {a }}$, You-yuan Wang a , Zhao-yu Lin a , Han-qing Zhang a , Da-ming Zhang a , \\ Xin $\mathrm{Yu}^{\mathrm{a}}$, Fa-ya Liang ${ }^{\mathrm{c}}$, Xiao-ming Huang ${ }^{\mathrm{c}}$, Eduardo Dias-Ribeiro ${ }^{\mathrm{d}}$, Yong Liu ${ }^{\mathrm{e}}$, \\ Xiang-hua Lin ${ }^{\mathrm{e}}$, Bin Zhou ${ }^{\mathrm{a}}$, Qi-xiang Liang ${ }^{\mathrm{a}}$, Celso Koogi Sonoda ${ }^{\text {, }}$, Jin-song Li ${ }^{\text {a, b, * }}$ \\ a Department of Oral and Maxillofacial Surgery, Sun Yat-Sen Memorial Hospital of Sun Yat-Sen University, Guangzhou 510120, China \\ ${ }^{b}$ Guangdong Provincial Key Laboratory of Malignant Tumor Epigenetics and Gene Regulation of Sun Yat-Sen Memorial Hospital, Guangzhou 510120, China

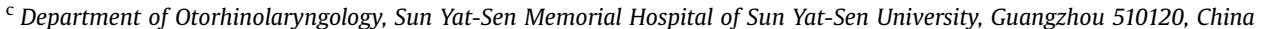 \\ d Department of Oral and Maxillofacial Surgery, Dental School of Araçatuba, Universidade Estadual Paulista (UNESP), Araçatuba, São Paulo, Brazil \\ e Morphologic \& Biochemical Lab of Pediatric Hematology, Sun Yat-Sen Memorial Hospital of Sun Yat-Sen University, Guangzhou 510120, China
}

\section{A R T I C L E I N F O}

\section{Article history:}

Paper received 27 April 2016

Accepted 30 November 2016

Available online 7 December 2016

\section{Keywords:}

Immune response

Surgical stress

Endoscopically assisted selective neck

dissection

Oral squamous cell carcinoma

\begin{abstract}
A B S T R A C T
Background: Endoscopically assisted selective neck dissection (SND) has recently been applied in clinical NO cases of oral squamous cell carcinoma (OSCC). However, nothing is known of the immune response after surgery.

Methods: A total of 60 patients with cT1-2N0 OSCC randomly underwent endoscopically assisted SND and open operations. The serum levels of IL-6, IL-8, IL-10, IL-1b, TNF-a, CRP, cortisol, ACTH, and growth hormone were analyzed before the start of the surgery (T0) and at 2 (T1), 6 (T2), 24 (T3), and 72 h (T4) after surgery.

Results: A total of 31 patients were randomized for endoscopic SND, whereas 29 underwent open procedures. The release of IL-6, IL-10 and CRP was significantly lower in the endoscopic group than in the open surgery group ( $p<0.05$ ), and cortisol levels were also lower in the endoscopic group $(p<0.05)$. Conclusions: Endoscopic SND could effectively provide lower inflammatory responses and surgical stress, reducing peri-operative trauma and accelerating recovery.
\end{abstract}

๑) 2016 Published by Elsevier Ltd on behalf of European Association for Cranio-Maxillo-Facial Surgery.

\section{Introduction}

An increasing number of studies have demonstrated that surgical trauma causes a host inflammatory reaction or disturbs the immunological balance (Lenz et al., 2007; Veenhof et al., 2012; Wang et al., 2012; Narita et al., 2013). Under surgical stress and immune compromise, pro- and anti-inflammatory cytokines are released, and systemic inflammatory response syndrome can result in post-operative morbidity and adverse effects such as fever and pain, as well as cardiopulmonary, infective, and thromboembolic

\footnotetext{
*Corresponding author. Department of Oral and Maxillofacial Surgery, Sun Yat-Sen Memorial Hospital of Sun Yat-Sen University, Guangzhou 510120, China. ** Corresponding author.

E-mail addresses: drchen@vip.163.com (W.-l. Chen), lijs2015@yeah.net (J.-s. Li).

${ }^{1}$ These authors contributed equally to this work.
}

complications (Herzum and Renz, 2008; Veenhof et al., 2012). In certain severe forms, the systemic inflammation can cause failure of one or several vital organs (Dewar et al., 2009) because surgical trauma-induced endocrine and metabolic changes are thought to mediate increased demands on organ function (Veenhof et al., 2012). Additionally, multiple organ dysfunction syndrome (MODS) can be a consequence of trauma after severe systemic inflammation. Several mechanisms have been proposed for the functional deficiencies of tumor-associated immune function in oral cancer patients (Jewett et al., 2006). Consequently, it might be advantageous to use a surgical technique with less immunological impact for oral squamous cell carcinoma (OSCC) treatment.

Interleukin-6 (IL-6) is a cytokine with both pro- and antiinflammatory abilities. It is associated with surgical complications and is a predictor of morbidity after surgical intervention 
(Veenhof et al., 2012; Kvarnstrom et al., 2013). IL-6 is considered a poor prognostic factor in oral cancer, and its secretion is facilitated by the tumor microenvironment (Culig, 2013). IL-8 is a proinflammatory interleukin that is significantly higher in patients with OSCC than in patients with chronic periodontitis or healthy controls (Punyani and Sathawane, 2013; Lisa et al., 2014). IL-10 is an anti-inflammatory interleukin that plays an important role in the development of oral cancer (Yao et al., 2008). Interleukin-1 $\beta$ (IL-1 $\beta$ ) is a critical mediator of chronic inflammation and is implicated in many cancers. IL-1 $\beta$ has been reported to promote malignant transformation and tumor aggressiveness in OSCC (Lee et al., 2015). Tumor necrosis factor (TNF)- $\alpha$ is pro-inflammatory and induces an acute phase reaction with local and systemic inflammation (Aggarwal et al., 2006). Increasing TNF- $\alpha$ is related to histological grading and clinical staging in OSCC (Krishnan et al., 2014). C-reactive protein (CRP) is perhaps the most well known acute phase reactant and is closely related to the inflammatory response, extent of tissue trauma, and activity of the immune reaction (Veenhof et al., 2012). Cortisol (Moris et al., 2014), adrenocorticotropic hormone (ACTH) (Tacconi et al., 2010) and growth hormone (Veenhof et al., 2012) are associated with surgical stress, which is widespread in clinical practice.

Laparoscopic rectectomies (Kvarnstrom et al., 2013), colectomies (Tsamis et al., 2012; Veenhof et al., 2012; Wang et al., 2012), and prostatectomies (Narita et al., 2013) are superior to open operations with respect to reducing the amount of intraoperative bleeding and relieving post-operative pain, thereby reducing the surgical stress reaction, improving pulmonary function, promoting post-operative rehabilitation, and decreasing the postoperative length of the hospital stay. Over the past 20 years, advancements in endoscopic and robot-assisted procedures have allowed alternative, smaller, or even complete avoidance of neck incisions in OSCC selective neck dissection (SND) (Kim et al., 2012; Lee et al., 2012; Tae et al., 2013; Byeon et al., 2014). These surgeries for SND are actually more invasive than traditional direct open neck approaches but produce desirable neck cosmesis at the cost of more soft tissue dissection, increased postoperative pain, and longer operative times (Kim et al., 2012; Lee et al., 2012; Tae et al., 2013). Recently, aiming to strike a balance between scarless surgery and minimal invasiveness, we first performed endoscopically assisted SND via a small submandibular approach, with satisfactory cosmetic results and minimal invasiveness, for patients with cT1-2N0 OSCC (Fan et al., 2014). However, whether our procedure produces minimal postoperative systemic immune response and surgical stress is unclear. To the best of our knowledge, there have been no studies focusing on the effects of endoscopic or robotassisted SND on post-operative immune function in OSCC patients.

The objective of the present study was therefore to determine the effects of endoscopically assisted SND on the systemic inflammatory response and surgical stress in OSCC patients.

\section{Materials and methods}

A total of 60 patients with early-stage OSCC in the Department of Oral and Maxillofacial Surgery of Sun Yat-Sen Memorial Hospital, between August 2012 and March 2013, were enrolled in this prospective study (Chictr.org/cn, ChiCTR-TRC-11001335). The inclusion criteria were as follows: no diseases of the immune system, no history of operations on the neck and distant metastases, no preoperative radiotherapy or chemotherapy, and an American Society of Anesthesiology (ASA) score of I through III. Patients who had distant metastasis at the time of diagnosis or recurrence of OSCC, were receiving other anti-cancer therapy, needed reconstruction of the primary site with free flap surgery, had a primary tumor in the midline area, or were not agreeable to providing blood samples were excluded.

The patients were randomly divided into two treatment groups: endoscopically assisted SND via a small submandibular incision, or open SND via a transcervical approach. The SND included level I, II, and III. All patients received general anesthesia with standardized anesthetic techniques. The surgical technique has been described in our previous study (Fan et al., 2014).

Peripheral blood and serum were collected at five different time points. The first sample (T0) was taken after the induction of anesthesia and before the start of the surgery (baseline). The second sample (T1) was taken $2 \mathrm{~h}$ after the start of surgery. The third sample (T2) was taken $6 \mathrm{~h}$ after the start of surgery. The fourth sample (T3) was taken $24 \mathrm{~h}$ after the start of surgery. The final sample (T4) was taken in the late postoperative period $72 \mathrm{~h}$ postsurgery. Serum samples for IL-6, IL-8, IL-10, IL-1 $\beta$, TNF- $\alpha$, CRP, cortisol, ACTH, and growth hormone analysis were obtained by centrifugation for $10 \mathrm{~min}$ at $3000 \mathrm{rpm}$ at $4{ }^{\circ} \mathrm{C}$. All samples were stored in aliquots at $-80^{\circ} \mathrm{C}$ until testing via a one-block design.

\subsection{Immunologic parameters}

The IL-6, IL- 8 , IL-10, IL- $1 \beta$, and TNF- $\alpha$ concentrations in the serum were measured using commercially available chemiluminescence immunoassay kits (YZB/UK 2496-2011, YZB/UK 3068-2011, YZB/UK 1809-2011, YZB/UK 1812-2011, YZB/UK 26142012; Siemens Healthcare Diagnostics Products Limited, Gwynedd, UK). The serum CRP levels were measured via chemiluminescence immunoassay kits (YZB/GEM 4345-2012, Siemens Healthcare Diagnostics Products GmbH, Marburg, Germany).

\subsection{Stress response}

The cortisol concentrations in the serum were measured by chemiluminescence immunoassay kits (YZB/USA 5709-2012, Siemens Healthcare Diagnostics Inc., Walpole, MA, USA). The ACTH and the growth hormone concentrations in the serum were measured by chemiluminescence immunoassay kits (L2KAC2, Siemens Healthcare Diagnostics Inc., Walpole, MA, USA) and (YZB/ USA 4219-2012, Siemens Healthcare Diagnostics Inc., Los Angeles, CA, USA), respectively.

\subsection{Statistical analysis}

A visual analog scale (VAS) (Fan et al., 2014) was used to score postoperative pain. Statistical analyses were performed using the SPSS 19.0 package (SPSS, Chicago, IL, USA). The means, standard deviation (SD), and ranges were calculated and subsequently shown when appropriate. Chi-square tests, Mann-Whitney U tests, and analysis of variance (ANOVA) were applied for group comparisons when appropriate. A p value of $<0.05$ indicates statistical significance.

\section{Results}

\subsection{Patients}

A total of 31 patients were randomized for endoscopically assisted SND, whereas 29 patients underwent open SND. The patient characteristics in terms of age, sex, body mass index (BMI), ASA score, operative procedure, and treatment outcomes were comparable for both groups and are depicted in Table 1. There were no significant differences between the two groups regarding age, sex, BMI, or ASA score. No significant differences between the two groups were found for intraoperative blood loss and all 
Table 1

Peri-operative data and treatment outcomes.

\begin{tabular}{|c|c|c|c|}
\hline Variable & $\begin{array}{l}\text { Endoscopic } \\
(\mathrm{n}=31)\end{array}$ & $\begin{array}{l}\text { Open } \\
(n=29)\end{array}$ & $\mathrm{p}$ \\
\hline Age, mean (range), y & $54.8(26.5-66.6)$ & $52.3(31.4-64.9)$ & 0.826 \\
\hline Sex, male:female & $22: 9$ & $16: 13$ & 0.205 \\
\hline BMI, mean (range) & $24.8(19-27)$ & $23.2(20-27)$ & 0.512 \\
\hline ASA score & & & 0.744 \\
\hline I & 9 & 11 & \\
\hline II & 19 & 16 & \\
\hline III & 3 & 2 & \\
\hline $\begin{array}{l}\text { Length of incision } \\
\text { [cm (range)] }\end{array}$ & $4.1(3.0-5.2)$ & $15.4(9.8-21.3)$ & $<0.001$ \\
\hline $\begin{array}{l}\text { Operation time } \\
\text { [min (range)] }\end{array}$ & $114.6(98.5-153.4)$ & $73.5(55.0-110.6)$ & $<0.001$ \\
\hline $\begin{array}{l}\text { Intraoperative } \\
\text { blood loss (ml) }\end{array}$ & $54.8(48.5-89.5)$ & $60.7(38.5-78.5)$ & 0.327 \\
\hline Amount of drainage $(\mathrm{ml})$ & $165.8(80.5-205.0)$ & $213.2(68.5-312.5)$ & 0.043 \\
\hline Duration of drainage (days) & $3.2(2.0-4.5)$ & $4.5(3.5-6.5)$ & 0.036 \\
\hline All complications & & & 0.459 \\
\hline Numbness of earlobe & 1 & 4 & \\
\hline $\begin{array}{l}\text { Temporary mouth } \\
\text { corner deviation }\end{array}$ & 4 & 3 & \\
\hline Seroma/hematoma & 0 & 1 & \\
\hline Wound infection & 0 & 1 & \\
\hline Pneumonia & 2 & 0 & \\
\hline Postoperative pain Score & $4.5(2.3-7.2)$ & $6.8(4.5-8.6)$ & 0.019 \\
\hline Hospital stay (days) & $6.9(5.5-9.6)$ & $8.2(6.5-13.5)$ & 0.006 \\
\hline
\end{tabular}

BMI, body mass index; ASA, American Society of Anesthesiology.

complications. However, other surgical parameters and outcomes, including the length of incision, amount and duration of drainage, postoperative pain score, and hospital length of stay but not the duration of the operative procedure, indicated that endoscopically assisted SND was superior to open SND.

\subsection{Immune status}

Based on the total number of blood sample accrual times described by the protocol, a total of 60 patients should yield 2700 values based on nine cytokine and hormone measurements per patient at one time point. A total of 23/2700 (0.09\%) values were missing, mainly due to time delays and improper sample preparation. Table 2 shows the means and ranges for each cytokine by both group and time point.
IL-6, IL-8, IL-10, TNF- $\alpha$, and CRP are released during endoscopic and open SND. The post-operative IL-6 and CRP concentrations were significantly higher in the open group compared with the endoscopic group at T1, T2, T3, and T4 (Table 2; Fig. 1A and C), whereas the IL-10 (Table 2; Fig. 1B) and TNF- $\alpha$ (Table 2) changes were similar to the former at the early stages (T1, T2, and T3) and (T1 and T2) after surgery and then immediately decreased. The mean IL-6, IL-10, TNF- $\alpha$, and CRP levels for the combined postoperative time intervals are given in Table 3. Only changes in IL-6, IL-10, and CRP showed significant differences between the two groups.

\subsection{Stress response}

By comparing the concentration changes in cortisol, ACTH, and growth hormone between the two groups, we found that only cortisol was significantly lower in the endoscopic group at T1, T2, and T3 (Table 2; Fig. 1D). The mean cortisol level for the combined postoperative time intervals also showed a significant difference, which is shown in Table 3.

\section{Discussion}

Surgical trauma and stress are very important for patients with malignant diseases, because it is well-known that abnormal postoperative immune activity may lead to an increased occurrence of post-operative infections and metastasis of tumor cells, as circulating tumor cells are at their highest concentrations directly after the onset of surgery (Wind et al., 2009). Therefore, numerous studies have suggested a biological substrate in response to the long-standing question of why cancer patients undergoing minimally invasive surgery have an accelerated recovery (Veenhof et al., 2012; Kvarnstrom et al., 2013; Narita et al., 2013) or even improved survival (Lacy et al., 2008; Novitsky et al., 2004).

In the field of head and neck surgery, the first endoscopically assisted operation was performed by Gagner (1996). Endoscopic techniques provide a magnified, illuminated, and adequate operative view, and the surgeon may consequently identify pertinent anatomy more easily and thus perform a meticulous surgical dissection. Recently, robotic or endoscopic surgeries for SND have been applied in cases of head and neck cancer, including OSCC, oropharyngeal cancer, and parotid cancer (Kim et al., 2012; Lee

Table 2

Mean (range) concentrations of inflammatory and hormone variables by type of surgery and time point.

\begin{tabular}{|c|c|c|c|c|c|c|}
\hline Variable & Groups & T0 baseline & T1 $2 \mathrm{~h}$ & $\mathrm{~T} 26 \mathrm{~h}$ & T3 $24 \mathrm{~h}$ & $\mathrm{~T} 472 \mathrm{~h}$ \\
\hline \multirow[t]{2}{*}{ IL-6 $(0-5.9 \mathrm{pg} / \mathrm{ml})^{\mathrm{a}}$} & Endoscopic & $2.9(0.7-3.8)$ & $48.5(32.8-73.2)$ & $105.3(98.1-168.9)$ & $64.5(27.6-109.2)$ & $18.6(9.3-43.7)$ \\
\hline & Open & $2.5(0.8-4.1)$ & $170.4(108.7-225.1)$ & $146.2(93.2-196.2)$ & $105.6(76.2-166.7)$ & $54.3(21.4-76.1)$ \\
\hline \multirow[t]{2}{*}{$\mathrm{IL}-8(0-62 \mathrm{pg} / \mathrm{ml})^{\mathrm{a}}$} & Endoscopic & $10.9(3.4-21.5)$ & $69.5(41.5-98.6)$ & $77.2(39.7-89.8)$ & $12.4(2.3-19.8)$ & $5.6(1.7-10.6)$ \\
\hline & Open & $7.6(4.6-16.4)$ & $73.2(39.5-103.6)$ & $71.8(46.2-96.4)$ & $9.7(3.5-16.5)$ & $7.1(2.6-13.2)$ \\
\hline \multirow[t]{2}{*}{ IL-10 $(0-9.1 \mathrm{pg} / \mathrm{ml})^{\mathrm{a}}$} & Endoscopic & $3.2(0.6-6.2)$ & $16.7(10.6-36.7)$ & 31.7 (18.9-62.7) & $18.3(9.4-29.4)$ & $5.6(2.1-8.3)$ \\
\hline & Open & $2.4(0.4-5.7)$ & $108.1(56.8-168.5)$ & $67.5(41.5-92.7)$ & $34.6(23.4-45.7)$ & $4.8(1.3-6.7)$ \\
\hline \multirow[t]{2}{*}{$\operatorname{IL}-1 \beta(0-5 \mathrm{pg} / \mathrm{ml})^{\mathrm{a}}$} & Endoscopic & $2.2(0.4-3.8)$ & $3.8(1.0-4.6)$ & $2.6(0.5-3.8)$ & $3.7(0.6-4.9)$ & $2.4(0.4-4.9)$ \\
\hline & Open & $2.7(0.4-4.3)$ & $4.2(0.9-5.3)$ & $3.2(0.8-5.1)$ & $4.5(1.3-6.7)$ & $1.9(0.3-3.6)$ \\
\hline \multirow[t]{2}{*}{$\mathrm{TNF}-\alpha(0-8.1 \mathrm{pg} / \mathrm{ml})^{\mathrm{a}}$} & Endoscopic & $5.3(3.2-8.4)$ & $9.7(7.9-13.2)$ & $8.6(5.4-10.3)$ & $7.5(5.2-9.3)$ & $5.6(2.3-8.0)$ \\
\hline & Open & $4.7(2.8-8.6)$ & $14.3(8.5-23.4)$ & $12.6(6.7-18.9)$ & $6.8(3.7-9.2)$ & $5.3(3.1-7.2)$ \\
\hline \multirow[t]{2}{*}{$\mathrm{CRP}(0-5 \mathrm{mg} / \mathrm{L})^{\mathrm{a}}$} & Endoscopic & $1.7(0.2-3.6)$ & $14.2(6.7-21.6)$ & $31.8(23.6-40.1)$ & $53.3(38.1-69.4)$ & $49.8(29.8-67.1)$ \\
\hline & Open & $2.4(0.4-4.8)$ & $23.9(14.2-30.4)$ & $50.7(38.4-63.9)$ & $86.2(54.7-101.3)$ & $153.4(98.2-186.4)$ \\
\hline \multirow[t]{2}{*}{ Cortisol $(118.6-618 \mathrm{nmol} / \mathrm{L})^{\mathrm{a}}$} & Endoscopic & $459.7(132.8-609.7)$ & $769.5(629.7-804.5)$ & $896.7(648.3-912.5)$ & $461.9(120.9-583.6)$ & $506.4(186.2-637.5)$ \\
\hline & Open & $436.2(183.6-598.6)$ & $1006.1(726.9-1352.4)$ & $1276.8(786.8-1420.6)$ & $739.6(559.8-913.6)$ & $493.6(149.5-609.5)$ \\
\hline \multirow[t]{2}{*}{ ACTH $(0-46 \mathrm{pg} / \mathrm{ml})^{\mathrm{a}}$} & Endoscopic & $23.9(5.0-34.5)$ & $45.7(20.3-58.3)$ & $38.2(4.3-49.6)$ & $26.1(2.1-42.3)$ & $23.4(8.3-39.4)$ \\
\hline & Open & $16.3(6.4-27.6)$ & $51.6(30.4-67.3)$ & $43.5(23.5-64.8)$ & $31.6(6.2-49.8)$ & $19.8(8.2-36.7)$ \\
\hline \multirow[t]{2}{*}{ Growth hormone $(0-10 \mathrm{ng} / \mathrm{ml})^{\mathrm{a}}$} & Endoscopic & $5.2(0.8-8.9)$ & $6.4(0.9-8.9)$ & $9.6(0.2-13.3)$ & $8.9(0.4-14.2)$ & $4.3(0.6-8.7)$ \\
\hline & Open & $4.2(0.4-7.6)$ & $5.9(1.2-7.6)$ & $12.6(2.6-16.2)$ & $5.6(2.3-9.7)$ & $2.6(0.2-5.9)$ \\
\hline
\end{tabular}

IL, interleukin; TNF- $\alpha$, tumor necrosis factor- $\alpha$; CRP, C-reactive protein; ACTH, adrenocorticotropic hormone.

Values in bold indicate significant difference in concentration between the two treatment groups $(p<0.05)$.

a Normal value in healthy subjects. 

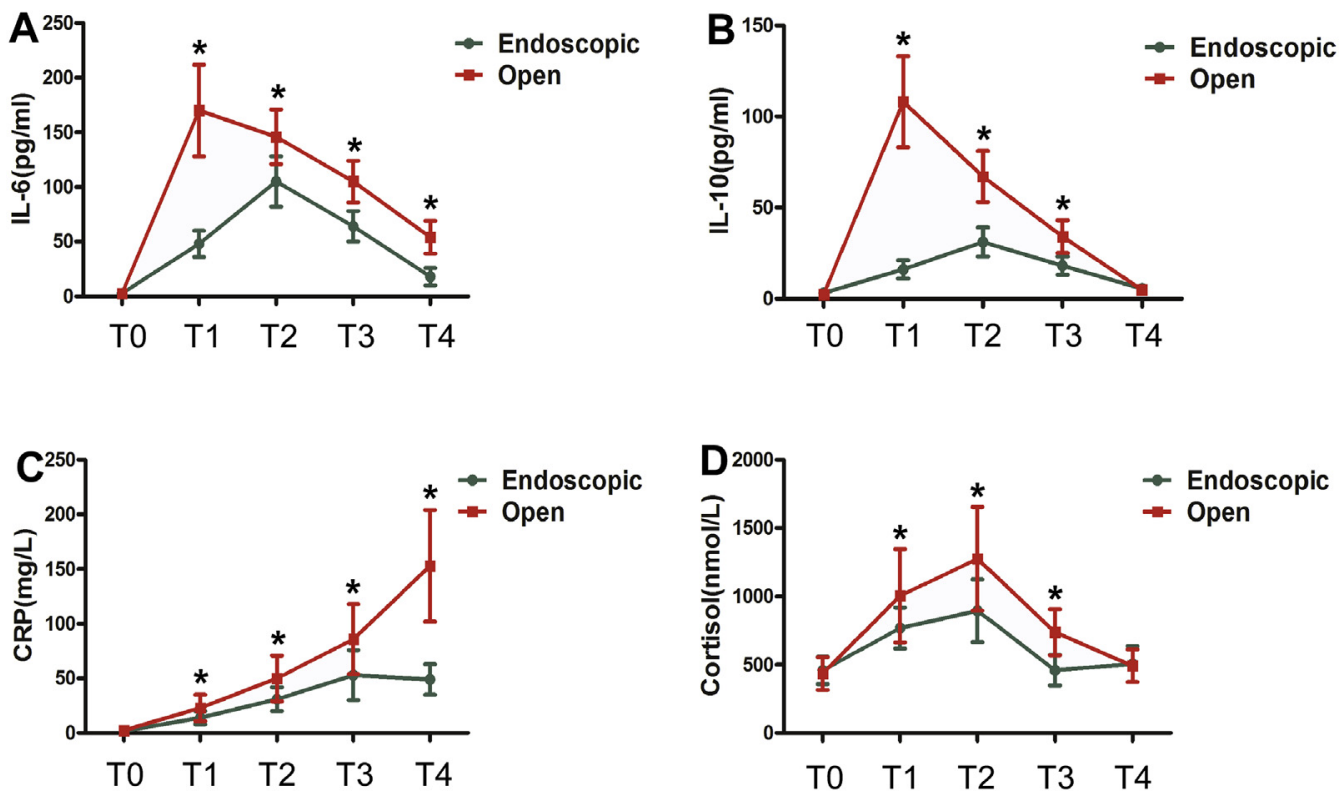

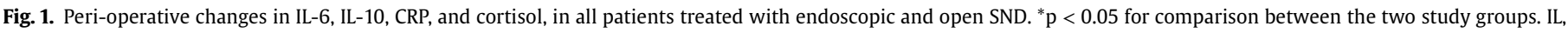

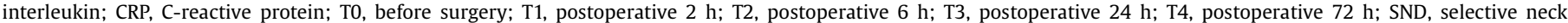
dissection.

et al., 2012; Tae et al., 2013; Byeon et al., 2014). However, considering the surgical invasiveness and cosmetic results, controversies related to such procedures remain, due to the long distance from the incision to the dissection levels as well as certain postoperative complications (Fan et al., 2014). To achieve minimal surgical invasiveness and satisfactory cosmetic results, we first performed endoscopically assisted SND via a small submandibular approach in patients with OSCC (Fan et al., 2014).

The present study was not designed to investigate the differences in clinical parameters between the endoscopic and open surgery groups. Based on the operative and hospital data, we can safely state that endoscopically assisted SND was superior to open SND based on the length of incision and patient recovery. To date, no previous studies have investigated the immune status and stress response, which correspond to the observed cosmetic results and faster recovery from minimally invasive SND.

The present study shows that both pro- and anti-inflammatory cytokines are released during endoscopic and open SND. Our study also shows that significantly lower levels of IL-6, IL-10, TNF- $\alpha$, and CRP are released in patients who undergo the endoscopic technique than in those who undergo open surgery. For the combined postoperative time intervals, IL-6, IL-10, and CRP were also significantly lower in the endoscopic group.

Table 3

Values (mean $\pm \mathrm{SD}$ ) for combination of post-operative time intervals.

\begin{tabular}{llll}
\hline Variable & Groups & Mean \pm SD & $\mathrm{p}$ \\
\hline IL-6 $(\mathrm{pg} / \mathrm{ml})$ & Endoscopic & $59.2 \pm 13.6$ & $<0.001$ \\
& Open & $119.1 \pm 21.4$ & \\
IL-10 $(\mathrm{pg} / \mathrm{ml})$ & Endoscopic & $18.1 \pm 3.5$ & 0.026 \\
& Open & $53.8 \pm 16.8$ & \\
TNF- $\alpha(\mathrm{pg} / \mathrm{ml})$ & Endoscopic & $7.9 \pm 1.6$ & 0.472 \\
& Open & $9.8 \pm 2.4$ & \\
CRP $(\mathrm{mg} / \mathrm{L})$ & Endoscopic & $37.3 \pm 13.6$ & 0.006 \\
& Open & $78.6 \pm 26.1$ & \\
Cortisol $(\mathrm{nmol} / \mathrm{L})$ & Endoscopic & $658.6 \pm 209.5$ & 0.037 \\
& Open & $879.0 \pm 312.9$ & \\
\hline
\end{tabular}

IL, interleukin; TNF- $\alpha$, tumor necrosis factor- $\alpha$; CRP, C-reactive protein.
IL-6 is considered a major mediator of the acute-phase protein response following injury or surgical invasion, and compared with other cytokines, the concentration of IL- 6 is most consistently increased in the circulation of patients (Tsamis et al., 2012). The serum IL-6 level after laparoscopic operations was significantly reduced compared with the open technique for rectectomies, colectomies, and prostatectomies. CRP is an anon-specific acutephase protein produced by the liver following trauma or inflammation. Indeed, the serum CRP level is increased in association with surgical trauma and stress (Wang et al., 2012). Therefore, measurement of the postoperative CRP level may reflect each surgical invasion and the degree of tissue trauma. Serum CRP levels after laparoscopic rectal surgery and colectomy have been shown to be significantly lower than those after open operations (Veenhof et al., 2012; Kvarnstrom et al., 2013). Bleeding is known to cause an inflammatory response. However, the intraoperative blood loss showed no significant difference between the two groups in the present study. We suggest that a possible explanation for the better immune preservation in endoscopically assisted SND is that the surgeon performed a very short incision and achieved an accurate identification and meticulous dissection. Consequently, patients in the endoscopic group had less drainage and experienced less postoperative pain and a shorter hospital stay.

The complex interaction between inflammatory cytokines and the sympathetic/adrenomedullary system or hypothalamicpituitary-adrenal axis is still difficult to assess (Veenhof et al., 2012; Moris et al., 2014). The simultaneous activation of these two systems allows the organism to adapt and to maintain or regain homeostasis during surgical stress. In the present study, we found that the postoperative levels of cortisol were lower in the endoscopic group than in the open group, which was also consistent with other studies of major abdominal surgery (Kataja et al., 2007). ACTH has been shown to be associated with high cortisol following major surgery in general (Dimopoulou et al., 2008). However, we did not find any significant difference between the two types of surgery postoperatively. No significant difference was found between the two groups in the current study regarding growth 
hormone levels, and Veenhof et al. (2012) also found that the postoperative levels of growth hormone could be attributed to the type of aftercare but not the surgical procedure in colectomies. Therefore, the two types of procedure in the present study may cause the release of different levels of cortisol, but not of ACTH and growth hormone. However, their metabolized products may be interesting to evaluate in a future study.

Finally, considering immune maintenance and the lower level of surgical stress in minimally invasive surgery, the ambiguous viewpoints regarding port-site tumor recurrence, slow adoption of the method, and oncologic equivalency with its open counterpart have been well proved in randomized trials in colon and rectal cancer patients (Barlehner et al., 2005; Buunen et al., 2009). In our previous study, patients in the two groups did not present with any significant difference in regional metastasis during approximately 3 years of follow-up. However, whether the extent of the surgical trauma and its immunological consequences really has an impact on the oncological safety and patient survival is not fully known and requires further investigation.

\section{Conclusion}

The pro- and anti-inflammatory responses and surgical stress for SND were lower in endoscopic surgery than in the open procedure. This study is the first to reveal that endoscopically assisted SND via a small submandibular approach protects the postoperative immune system and yields accelerated recovery. The study further demonstrates that this procedure could reduce surgical trauma and provide minimal invasiveness. However, further studies are needed to investigate the long-term outcomes, oncological safety, and patient survival.

\section{Conflict of interest}

The authors declare no conflict of interest.

\section{Acknowledgements}

This work was supported by Grant [2013]163 from Key Laboratory of Malignant Tumor Molecular Mechanism and Translational Medicine of Guangzhou Bureau of Science and Information Technology, Grant KLB09001 from the Key Laboratory of Malignant Tumor Gene Regulation and Target Therapy of Guangdong Higher Education Institutes, the Sun Yat-Sen University Clinical Research 5010 Program (2010008, to Prof. Xiao-Ming Huang), National key clinical specialty (oral and maxillofacial surgery), National Natural Science Foundation of China Grant (81472521, 81272951 and 81072225, to Prof. Jin-song Li; (81172563 to Prof. Wei-liang Chen, and 81402251, to Dr. Song Fan).

\section{References}

Aggarwal BB, Shishodia S, Sandur SK, Pandey MK, Sethi G: Inflammation and cancer: how hot is the link? Biochem Pharmacol 72: 1605-1621, 2006

Barlehner E, Benhidjeb T, Anders S, Schicke B: Laparoscopic resection for rectal cancer: outcomes in 194 patients and review of the literature. Surg Endosc 19: 757-766, 2005

Buunen M, Veldkamp R, Hop WC, Kuhry E, Jeekel J, Haglind E, et al: Survival after laparoscopic surgery versus open surgery for colon cancer: long-term outcome of a randomised clinical trial. Lancet Oncol 10: 44-52, 2009

Byeon HK, Holsinger FC, Koh YW, Ban MJ, Ha JG, Park JJ, et al: Endoscopic supraomohyoid neck dissection via a retroauricular or modified facelift approach: preliminary results. Head Neck 36: 425-430, 2014

Culig Z: Interleukin-6 as a therapy target in oral squamous carcinoma. Expert Opin Ther Targets 17: 53-59, 2013
Dewar D, Moore FA, Moore EE, Balogh Z: Postinjury multiple organ failure. Injury 40: 912-918, 2009

Dimopoulou I, Tzanela M, Vassiliadi D, Mavrou I, Kopterides P, Orfanos S, et al: Pituitary-adrenal responses following major abdominal surgery. Hormones (Athens) 7: 237-242, 2008

Fan S, Liang FY, Chen WL, Yang ZH, Huang XM, Wang YY, et al: Minimally invasive selective neck dissection: a prospective study of endoscopically assisted dissection via a small submandibular approach in cT(1-2_N(0) oral squamous cell carcinoma. Ann Surg Oncol 21: 3876-3881, 2014

Gagner M: Endoscopic subtotal parathyroidectomy in patients with primary hyperparathyroidism. Br J Surg 83: 875, 1996

Herzum I, Renz H: Inflammatory markers in SIRS, sepsis and septic shock. Curr Med Chem 15: 581-587, 2008

Jewett A, Head C, Cacalano NA: Emerging mechanisms of immunosuppression in oral cancers. J Dent Res 85: 1061-1073, 2006

Kataja J, Chrapek W, Kaukinen S, Pimenoff G, Salenius JP: Hormonal stress response and hemodynamic stability in patients undergoing endovascular vs. conventional abdominal aortic aneurysm repair. Scand J Surg 96: 236-242, 2007

Kim WS, Lee HS, Kang SM, Hong HJ, Koh YW, Lee HY, et al: Feasibility of robotassisted neck dissections via a transaxillary and retroauricular ("TARA") approach in head and neck cancer: preliminary results. Ann Surg Oncol 19: 1009-1017, 2012

Krishnan R, Thayalan DK, Padmanaban R, Ramadas R, Annasamy RK, Anandan N: Association of serum and salivary tumor necrosis factor-alpha with histological grading in oral cancer and its role in differentiating premalignant and malignant oral disease. Asian Pac J Cancer Prev 15: 7141-7148, 2014

Kvarnstrom A, Swartling T, Kurlberg G, Bengtson JP, Bengtsson A: Pro-inflammatory cytokine release in rectal surgery: comparison between laparoscopic and open surgical techniques. Arch Immunol Ther Exp (Warsz) 61: 407-411, 2013

Lacy AM, Delgado S, Castells A, Prins HA, Arroyo V, Ibarzabal A, et al: The long-term results of a randomized clinical trial of laparoscopy-assisted versus open surgery for colon cancer. Ann Surg 248: 1-7, 2008

Lee CH, Chang JS, Syu SH, Wong TS, Chan JY, Tang YC, et al: IL-1beta promotes malignant transformation and tumor aggressiveness in oral cancer. I Cell Physiol 230: 875-884, 2015

Lee HS, Kim WS, Hong HJ, Ban MJ, Lee D, Koh YW, et al: Robot-assisted supraomohyoid neck dissection via a modified face-lift or retroauricular approach in early-stage cNO squamous cell carcinoma of the oral cavity: a comparative study with conventional technique. Ann Surg Oncol 19: 3871-3878, 2012

Lenz A, Franklin GA, Cheadle WG: Systemic inflammation after trauma. Injury 38: 1336-1345, 2007

Lisa CY, Jordan L, Gorugantula LM, Schneiderman E, Chen HS, Rees T: Salivary interleukin-6 and -8 in patients with oral cancer and patients with chronic oral inflammatory diseases. J Periodontol 85: 956-965, 2014

Moris DN, Kontos MI, Mantonakis EI, Athanasiou AK, Spartalis ED, Bakoyiannis CN, et al: Concept of the aortic aneurysm repair-related surgical stress: a review of the literature. Int J Clin Exp Med 7: 2402-2412, 2014

Narita S, Tsuchiya N, Kumazawa T, Maita S, Numakura K, Obara T, et al: Comparison of surgical stress in patients undergoing open versus laparoscopic radica prostatectomy by measuring perioperative serum cytokine levels. J Laparoendosc Adv Surg Tech A 23: 33-37, 2013

Novitsky YW, Litwin DE, Callery MP: The net immunologic advantage of laparoscopic surgery. Surg Endosc 18: 1411-1419, 2004

Punyani SR, Sathawane RS: Salivary level of interleukin-8 in oral precancer and oral squamous cell carcinoma. Clin Oral Investig 17: 517-524, 2013

Tacconi F, Pompeo E, Sellitri F, Mineo TC: Surgical stress hormones response is reduced after awake videothoracoscopy. Interact Cardiovasc Thorac Surg 10 666-671, 2010

Tae K, Ji YB, Song CM, Min HJ, Kim KR, Park CW: Robotic selective neck dissection using a gasless postauricular facelift approach for early head and neck cancer: technical feasibility and safety. J Laparoendosc Adv Surg Tech A 23: 240-245, 2013

Tsamis D, Theodoropoulos G, Stamopoulos P, Siakavellas S, Delistathi T, Michalopoulos NV, et al: Systemic inflammatory response after laparoscopic and conventional colectomy for cancer: a matched case-control study. Surg Endosc 26: 1436-1443, 2012

Veenhof AA, Vlug MS, van der Pas MH, Sietses C, van der Peet DL, de Lange-de KE, et al: Surgical stress response and postoperative immune function after laparoscopy or open surgery with fast track or standard perioperative care: a randomized trial. Ann Surg 255: 216-221, 2012

Wang G, Jiang Z, Zhao K, Li G, Liu F, Pan H, et al: Immunologic response after laparoscopic colon cancer operation within an enhanced recovery program. J Gastrointest Surg 16: 1379-1388, 2012

Wind J, Tuynman JB, Tibbe AG, Swennenhuis JF, Richel DJ, van Berge HM, et al: Circulating tumour cells during laparoscopic and open surgery for primary colonic cancer in portal and peripheral blood. Eur J Surg Oncol 35: 942-950, 2009

Yao JG, Gao LB, Liu YG, Li J, Pang GF: Genetic variation in interleukin-10 gene and risk of oral cancer. Clin Chim Acta 388: 84-88, 2008 